\title{
Modified latex agglutination test for antibodies to Toxoplasma gondii in eluates from Guthrie cards
}

\author{
S P Parker, W D Cubitt
}

Abstract

Aims: To determine whether the Eiken particle agglutination test could be modified to make it sufficiently sensitive to screen blood samples collected on Guthrie cards for the presence of antibodies to Toxoplasma gondii; to evaluate the specificity of the modified system; and to compare seroepidemiological data on the prevalence of $T$ gondii in pregnant women. Methods: Simulated dried blood spots were prepared from sera from pregnant women booking for antenatal care. Eluates from the simulated dried blood spot cards and sera were tested in parallel using the modified test ( 1 in 5 dilution of latex) and the standard assay (neat latex particles) and endpoints determined. Guthrie card eluates, from neonates in three Thames regions, were then tested using the modified test.

Results: The modified test produced a $4 \cdot 21$-fold increase in antibody titre in 85 sera when tested in parallel with the standard test. Eluates of $168 / 170$ from simulated dried blood spots derived from seropositive patients gave a positive result in the modified test. The two eluates which gave a negative result were derived from patients with an equivocal titre of $1 / 16$ in the standard serum test. Of the eluates derived from serum negative patients all 103 were negative at a dilution of 1 in 4 in the modified test. The seroprevalence of antibodies to $\boldsymbol{T}$ gondii in pregnancy was $21.8 \%$ using the standard test. A similar value of $20.5 \%$ was obtained when dried blood spots from neonates in a similar region of London were tested by the modified test.

Conclusions: The modified Eiken Toxoreagent test is sensitive, simple, and economic for screening large numbers of dried blood spots. The procedure could be easily semiautomated and the technique applied to the mass screening of neonatal blood samples collected on Guthrie cards to determine the seroprevalence of $T$ gon-

Virology Department, Institute of Child

Health, 30 Guilford

Street, London WC1N $1 \mathrm{EH}$

$S$ P Parker

W D Cubit

Correspondence to:

Dr Cubitt

Accepted for publication 6 April 1992
It has been suggested recently that the true extent of problems associated with congenital toxoplasmosis infection are being overlooked. As a result, the proposed introduction of a programme for screening pregnant women in the United Kingdom has provoked controversy.

The epidemiology of Toxoplasma gondii in women has been reviewed, ${ }^{1-3}$ and serological studies have shown a wide variation in the prevalence of antibodies in European countries: France $80 \%^{4}$; Belgium $50 \%{ }^{5}$; Netherlands $40 \%^{6}$; Finland $19 \%^{7}$; and England $19 \%{ }^{8}$ However, seroprevalence has fallen rapidly over the past 20 years in Sweden ${ }^{9}$ and in parts of England. ${ }^{10}$ Inexpensive and effective methods of surveillance are reported to monitor changes in seroprevalence so that appropriate strategies to prevent infection can be implemented.

Blood collected from neonates on Guthrie cards has been used for many years in the United Kingdom and the United States of America for screening for the presence of metabolic diseases. ${ }^{112}$ Such samples have been used in the USA for seroepidemiology studies of the prevalence of antibodies to HIV1 in pregnant women. ${ }^{1314}$ To reduce the cost of neonatal screening in the United Kingdom the Fujirebio anti-HIV-1 particle agglutination assay was modified. ${ }^{15}$ Its efficacy has been confirmed for the determination of the prevalence of maternal HIV-1 infection based on unlinked anonymous testing of neonates. ${ }^{16-18}$ As a result of our experience with the modified HIV-1 test, we decided to evaluate the use of the Toxoreagent latex agglutination test, which we modified in a similar way.

\section{Methods}

SOURCE OF SERA

Positive $(n=170)$ and negative $(n=103)$ sera were obtained from pregnant women when they booked in at an antenatal clinic in inner London. These samples had previously been screened for the presence of antibodies to $T$ gondii. Sera had been stored at $-20^{\circ} \mathrm{C}$ and frozen and thawed several times during the past 10 years for other studies ${ }^{81920}$ but not heat inactivated.

\section{SOURCE OF NEONATAL SAMPLES}

Dried blood spot samples were obtained from Guthrie cards which had been collected from 1023 neonates for routine metabolic screening. These samples originated from health districts in the inner London area. Samples were collected during 1991 and stored at $4^{\circ} \mathrm{C}$ in sealed bags for a period of up to one month, before testing. 


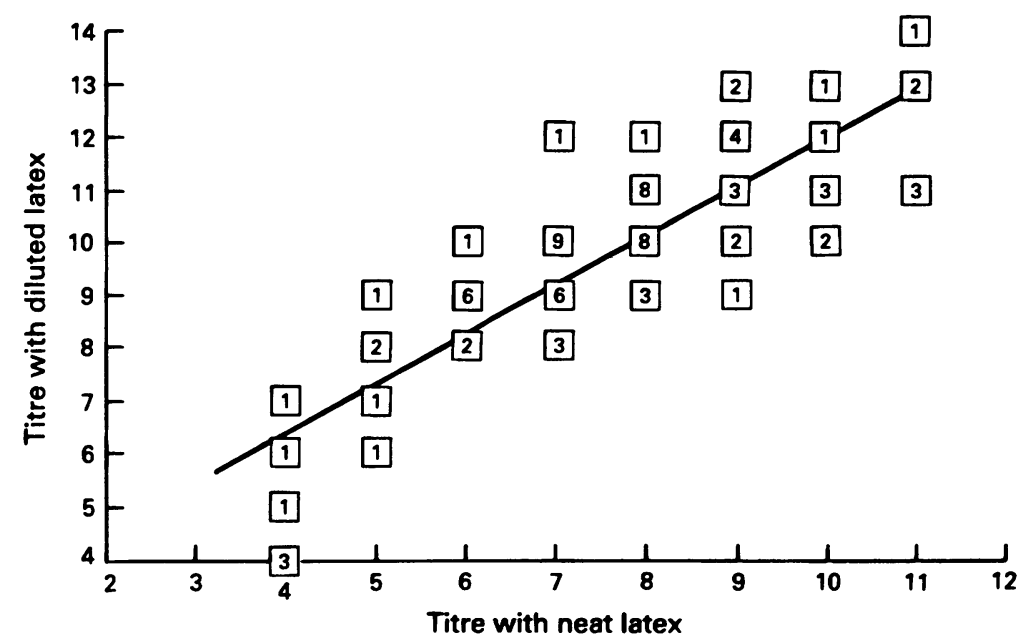

Figure 1 Comparison of 85 antibody titres in sera using neat or diluted (1 in 5) latex. Data expressed in log base 2.

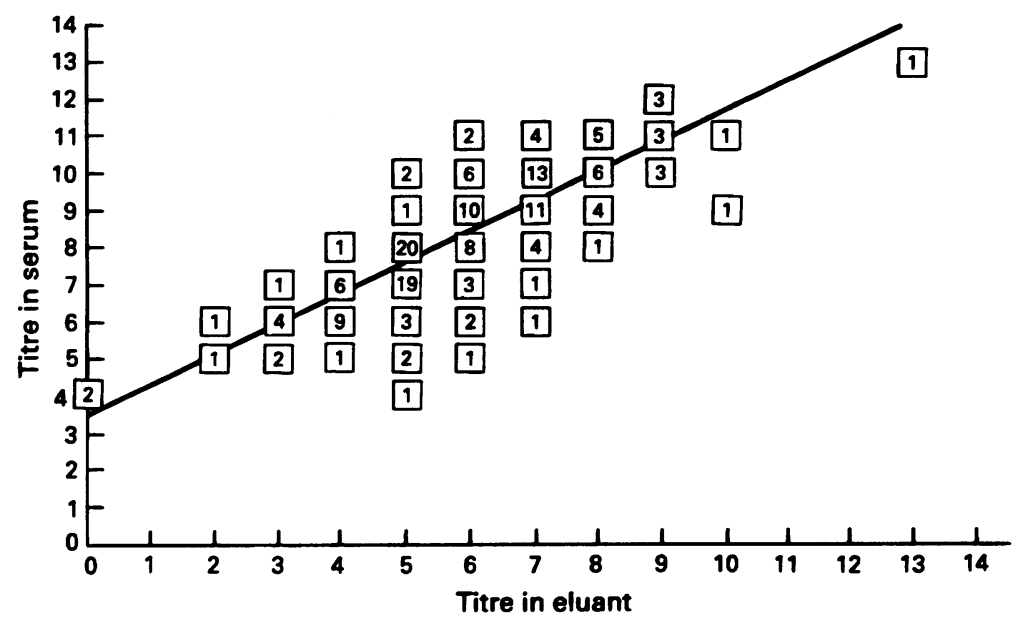

Figure 2 Distribution of titres obtained in 339 antenatal sera and 338 Guthrie cord eluates.

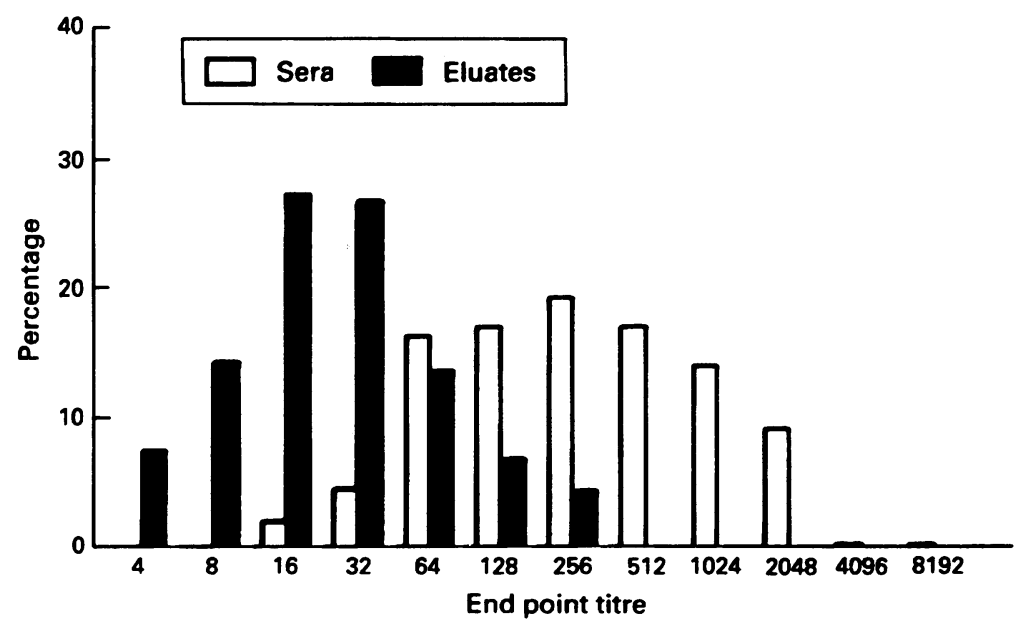

Figure 3 Comparison of 170 antibody titres in sera and Guthrie card eluates. Data expressed in log base 2. hours, then stored at $4^{\circ} \mathrm{C}$ in sealed bags.

\section{ELUTION}

A 5.5-6.0 mm diameter blood spot was punched out of each Guthrie card circle and placed in the well of a flat bottomed microtitre plate. The dried blood was then eluted in $100 \mu \mathrm{l}$ of buffer (phosphate buffered saline, pH $7 \cdot 2$, containing $0.05 \%$ Tween $20,0.005 \%$ sodium azide). Plates were shaken for 30 minutes, covered, and then left to eluate overnight at $4^{\circ} \mathrm{C}$. Plates were shaken again for three minutes before the eluate was removed for testing.

The Eiken test was used according to the manufacturer's instructions for testing sera.

MODIFIED TEST FOR GUTHRIE CARD BLOOD SPOTS The Eiken Toxoreagent latex agglutination test was modified by diluting the latex 1 in 5 in AMP buffer, 0.2 M 2-amino-2-methyl-1-propanol (HCl) (Sigma Ltd, UK).

Tests were performed according to the manufacturer's instructions but in $\mathrm{V}$ well microtitre plates. Following overnight incubation at room temperature the plates were placed on a light box sloped at an angle of $70^{\circ}$ and the results read after 10 minutes. Positive tests were distinguished by a tight discrete agglutination pattern; negative samples formed a teardrop pattern. Samples found to be positive in the initial screen were titrated in a series of doubling dilutions from 1 in 4 in AMP buffer to 1 in 8192 to obtain an endpoint.

\section{Results}

COMPARISON OF TITRES IN SERA OBTAINED USING NEAT LATEX AND A 1 IN 5 DILUTION OF LATEX PARTICLES

The results of tests on 85 sera are shown in fig 1. The mean value of the endpoints obtained using a 1 in 5 dilution of latex was $4 \cdot 21$ times greater than with neat latex. The agglutination patterns were easy to read and there was no evidence of false negative results when diluted latex was used.

COMPARISON OF ANTIBODY TITRES IN SERA TESTED BY THE STANDARD TECHNIQUE AND ELUATES FROM GUTHRIE CARDS USING LATEX AT A 1 IN 5 DILUTION The results of tests on 170 seropositive antenatal sera and corresponding eluates from simulated blood spots are shown in fig 2 . The mean value of titres in sera using the standard technique was $4 \cdot 13$ times greater than in the eluates from simulated blood spots.

Using the modified test 168 out of 170 $(98.8 \%)$ had detectable antibody titres $\left(\geqslant 4\left(>2 \log _{2}\right)\right)$. The two eluates in which antibody was not detected originated from patients that had equivocal titres of $1 / 16$ by the standard test.

A further 103 eluates from simulated antibody negative blood spots gave a negative result $\left(<4\left(<2 \log _{2}\right)\right)$ using the modified test.

Figure 3 compares the distribution of antibody titres in sera using the standard technique and in eluates from Guthrie cards using the modified assay. The results show a similar make 1 in 2 dilution of each of the antenatal serum samples provided. A $110 \mu$ aliquot of each dilution was spotted on to a 15-20 mm diameter circle on a Guthrie card and allowed to dry at room temperature for 24

PREPARATION OF SIMULATED DRIED BLOOD SPOTS Fresh whole blood was screened to ensure the absence of antibodies to $T$ gondii and used to 
antibody distribution curve in pregnant women and in a comparable sized sample of unrelated neonates. However, the endpoints of the eluates were four-to eight-fold lower, presumably due to the dilution factor involved. Using the standard test, 334 of 339 of the antibody positive sera had titres of $\geqslant 1 / 32$. The other five sera had low titres of $1 / 16$ which represents the cutoff value.

SEROPREVALENCE OF ANTIBODIES TO $T$ gondii IN PREGNANT WOMEN BY THE NEONATAL SCREENING OF GUTHRIE CARDS

The overall seroprevalence of antibodies to $T$ gondii when screening neonates using the modified technique on eluates from Guthrie cards was $20.5 \%$ (214 out of 1043). A similar value would be expected with the mothers, as neonatal blood contains maternal antibody.

\section{Discussion}

The Eiken Toxoreagent test has been evaluated and found to be both sensitive and specific. $^{821-23}$ It is widely used in the United Kingdom for screening sera, but has not been evaluated for screening samples collected on Guthrie cards.

The modified test detected $98.8 \%$ of all positive sera, giving $100.0 \%$ specificity when compared with the standard test. This is a sensitive and simple method for screening large numbers of samples. The prevalence of maternal antibody found in the present study of 1043 eluates from Guthrie cards was $20.5 \%$. This is similar to the figure of $21.8 \%$ obtained when sera were screened from 1000 pregnant women attending an antenatal clinic in London using the standard test. ${ }^{8}$

Using the standard Eiken test, sera with a titre of $1 / 16$ are regarded as weakly positive and testing a follow up sample is recommended. If a screening procedure was introduced, all negative samples would need to be followed up two to three times during pregnancy. Although the modified latex test failed to detect two simulated samples in which the sera had a titre of $1 / 16$, the outcome would be identical, as both these patients would have been retested. The standard technique was not sufficiently sensitive to detect low titres of antibody in eluates from Guthrie cards, but this problem was overcome by modifying the assay as described.

The advantages of the Eiken latex agglutination test are that it detects total antibody, is simple to perform, and requires no expensive capital equipment. The modified test retains these advantages and the cost is reduced from about 10 pence to 2 pence per well, between 50 and 100 times cheaper than many commercially available enzyme immunoassays.

The use of blood samples collected on Guthrie cards from both adults and babies also reduces the problems of transport and storage.
This makes the test ideal for epidemiological surveillance in the United Kingdom or third world countries.

The method described can be used to screen rapidly large numbers of samples and the procedures can easily be semiautomated. The modified assay is ideally suited to link in with other neonatal screening programmes which rely on the use of blood collected on Guthrie cards.

This project was supported by a grant from the Child Health Appeal Research Trust.

We thank Dr A Ades for his helpful advice and criticism.

1 Remington JS, Desmonts G. Toxoplasmosis. In: Remington JS, Kline JO, eds. Infectious diseases of the fetus and newborn infant. Philadelphia: W B Saunders, 1983:144-264.

2 Anonymous. Antenatal screening for toxoplasmosis in the UK. [Editorial] Lancet 1990;ii:346-7.

3 Joss AWL, Chatterton JMW, Ho-Yen DO. Congenital toxoplasmosis: to screen or not to screen? $\mathcal{F}$ Publ Health 1990;104:9-20.

4 Desmonts G, Couvreur J. Toxoplasmosis in pregnancy and its transmission to the fetus. Bull NY Acad Med 1974; 50:146-59.

5 Foulon W, Naessens A, Volckaert $M$, et al. Congenital toxoplasmosis: a prospective survey in Brussels. Br $f$ Obstet Gynaecol 1984;91:419-23.

6 van der Veen J, Polak MF. Prevalence of toxoplasma antibodies according to age with comments on the risk of infection. F Hyg 1980;85:165-74.

7 Lappalainen M, Koskela P, Hedman K, et al. Incidence of primary toxoplasma infections during pregnancy in southern Finland: a prospective cohort study. Scand $\tilde{f}$ Infect Dis 1992;24:97-104.

8 Cubitt WD, Ades AE, Peckham CS. An evaluation of five commercial assays for screening antenatal sera for the presence of antibodies to Toxoplasm gondii. 7 Clin Pathol 1992;45:435-8.

9 Forsgren M, Gille E, Ljungström I, Nokes DJ. Toxoplasma gondii antibodies in pregnant women in Stockholm in
1969,1979 and 1987 . Lancet 1991;337:1413-14.

10 Walker J, Noakes DJ, Jennings R. Longitudinal study of Toxoplasma seroprevalence in south Yorkshire. Epidemiol Toxoplasma seroprevalence

11 Levy HL. Newborn screening. In: Avery ME, Taeusch HW, eds. Scaffers' diseases of the newborn. 5 th edn. Philadelphia: W B Saunders, 1984:60-4.

12 Lemag Working Party. Estimation of blood phenylalanine from a dried blood spot using the Guthrie test. $\mathcal{f}$ Clin Pathol 1971;24:576-8.

13 Hoff R, Berardi VP, Weiblen BJ, et al. Seroprevalence of human immunodeficiency virus among childbearing women. N Engl f Med 1988;318:525-30.

14 Centers for Disease Control. CDC surveillance supplements. Morbidity Mortality Weekly Reports 1989;38:(no S-4).

15 Barbara JAJ, Salker R, Challis $P$, et al. Gelatin particle agglutination assay for HIV antibodies: a rapid economical modification with increased sensitivity. Med Lab Sci 1989;46:135-40.

16 Peckham CS, Tedder RS, Briggs M, et al. Prevalence of maternal HIV infection based on unlinked anonymous testing of newborn babies. Lancet 1990;335:516-19.

17 Ades AE, Parker S, Berry T, et al. Prevalence of maternal HIV-1 infection in Thames Regions: results from anonymous unlinked neonatal testing. Lancet 1991; 337:1562-5.

18 Tappin DM, Girdwood RWA, Follett EAC, et al. Prevalence of maternal HIV infection in Scotland based on unlinked anonymous testing of newborn babies. Lancet 1991;337:1565-7.

19 Peckham CS, Chin KS, Coleman JC, et al. Cytomegalovirus in pregnancy. Preliminary findings from a prospective in pregnancy. Preliminary find

20 Ades AE, Peckham CS, Dale GE, et al. Prevalence of antibodies to herpes simplex virus types 1 and 2 in pregnant women and estimated rates of infection. $\mathcal{J}$ Epidemiol Community Health 1989;43:53-60.

21 Balfour AH, Fleck DG, Hughes PA, Sharp D. Comparative study of three tests (dye test, indirect haemagglutination test, latex agglutination test) for the detection of antibodies to Toxoplasma gondii in human sera. 7 Clin Patho 1982;35:228-32.

22 Johnson J, Duffy K, New L, Holliman RE, Chessum BA, Fleck DG. Direct agglutination test and other assays for measuring antibodies to Toxoplasma gondii. $\mathcal{f}$ Clin Pathol measuring antibodic

23 Fleck DG. Diagnosis of toxoplasmosis. $f$ Clin Pathol 1989; 42:191-3. 


\section{CORRECTIONS}

Our apologies to Dr A K Singh (Bone marrow necrosis at transformation of chronic granulocytic leukaemia treated with interferon) $\mathcal{f}$ Clin Pathol 1992;45:830-1. The first initial of his name was inadvertently omitted.

An error appeared in the article Modified latex agglutination test for antibodies to Toxoplasma gondii in eluates from Guthrie cards by Drs S P Parker and W D Cubitt $(\mathcal{F}$ Clin Pathol 1992;45:907-9). The legends to figures 2 and 3 were transposed.
Postgraduate course in gynecologic and obstetric pathology with clinical correlation

April 26-30, 1993

The Departments of Pathology, Massachusetts General Hospital and Brigham and Women's Hospital, Harvard Medical School, will present a postgraduate course in gynecologic and obstetric pathology under the direction of Drs Robert E Scully, Robert H Young, and Christopher P Crum, to be held at the Four Seasons Hotel, Boston.

This course is designed for pathologists and obstetrician-gynecologists at resident and practitioner levels. It will provide an in-depth review of gynecologic and obstetric pathology with emphasis on morphologic diagnostic features and clinicopathologic correlation including management. Special attention will be paid to recent advances and newly recognised entities. Instruction will be primarily by lecture, but will also include case presentations and discussion periods. Each participant will receive a comprehensive course syllabus.

The fee for the course is $\$ 695.00$ (residents and fellows $\$ 550.00$ ). For further information contact: Department of Continuing Education, Harvard Medical School, 25 Shattuck Street, Boston, MA 02115 (Telephone: 617432-1525).

\section{ACP Locum Bureau}

The Association of Clinical Pathologists runs a locum bureau for consultant pathologists.

Applicants with the MRCPath who would like to do locums and anyone requiring a locum should contact The General Secretary, 221 Preston Road, Brighton BN1 6SA. Tel (0273) 561188 Fax (0273) 541227.

\section{British Lymphoma Pathology Group Tutorial \\ 14-16 April 1993}

Chilworth Manor Residential Conference Centre, Chilworth, Southampton

\section{NOTICES}

\begin{tabular}{|c|} 
First International \& Eighth \\
European \\
Conference on Clinical \\
Hemorheology \\
July 5-8, 1993 \\
Vienna, Austria \\
Local organising committee: \\
A Hansel, KL Resch, T Saradeth, \\
Congress Secretariat, Dept Phys Med \\
Rehab, University of Vienna (AKH), \\
Währinger Gürtel 18-20, A-1097 \\
Vienna, Austria. Tel: +43/1/40400-4330 \\
Fax: +43/1/40400-5281
\end{tabular}

The following will be offered this Spring by the Ernest Witebsky Center for

Immunology, University at Buffalo, State University of New York:

\section{Recombinant DNA technology:} Methods and applications

Hands-on laboratory course

Monday, April 19, through Sunday, April 25, 1993

This seven-day course, presented in conjunction with Exon-Intron, Inc., provides both fundamental and advanced training in recombinant DNA technology. It is designed to provide and expand laboratory skills in molecular cloning techniques for individuals with a background in biological sciences but who have little or no knowledge of recombinant DNA techniques. Course registration fee of $\$ 1,200.00$ covers course materials, beverage breaks, and seven (7) days' luncheons. Registration will be limited to 24 persons.

\section{Methods of immunologic research and diagnosis}

An at-the-bench laboratory training programme

\section{Monday, May 10, through}

Thursday, May 20, 1993

This 10-day programme consists of daily practical laboratory exercises personally carried out by participants, accompanied by lectures, demonstrations and discussions. Exercises range from the basic techniques of antiserum preparation to advanced techniques of immunoassay. Open to individuals at the postdoctoral level, supervisory senior technologists and graduate students. Course registration of $\$ 700.00$ includes course materials and beverage breaks. Registration will be limited to 36 individuals.

\section{Latex particle immunoassays \\ Hands-on laboratory course}

Friday and Saturday, May 21-22, 1993

This course is designed to provide an overview of preparation, formulation, properties and applications of latex particles in medical laboratory diagnosis. Geared toward laboratory researchers and technicians, and in-vitro diagnostic manufacturers. Course registration fee of $\$ 295.00$ covers course materials, beverage breaks, and lunch on both days. Registration will be limited to 24 persons.

For further information on any of the above courses, contact Roger $K$ Cunningham, PhD, Director, The Ernest Witebsky Center for Immunology, 442 Sherman Hall, University at Buffalo, 3435 Main Street, Buffalo, New York 14214 Phone: 716/829-2901 Fax: 716/829-2158. Because class size is limited in all courses, we recommend registrations be submitted at least one month prior to respective starting dates for best possibility of acceptance. 